\title{
WAAM system with interpass temperature control and forced cooling for near-net-shape printing of small metal components
}

\author{
Nejc Kozamernik ${ }^{1}$ - Drago Bračun ${ }^{1}$ (D) Damjan Klobčar ${ }^{1}$
}

Received: 8 April 2020 / Accepted: 17 August 2020 / Published online: 31 August 2020

(C) The Author(s) 2020

\begin{abstract}
In an attempt to find a solution similar to the FDM 3D printers which would allow cost-effective and reliable additive manufacturing of metal components, this paper proposes a three-axis WAAM system capable of reliably printing small, near-net-shape metal objects. The system consists of gas metal arc (GMA) process equipment, a three-axis CNC positioning system, the interpass temperature control and forced cooling of the base plate and the deposit. The main challenge addressed is the minimisation of shape distortions caused by excessive heat accumulation when printing small objects. The interpass temperature control uses an IR pyrometer to remotely measure the last deposited layer and a control system to keep the interpass temperature below the predefined value by stopping the deposition after each layer in order to allow the deposit to cool. This results in a stable and more repeatable shape of the deposit, even when the heat transfer conditions are changing during the build-up process. The combination of adaptive interlayer dwell time and forced cooling significantly improves system productivity. Open-source NC control and path generation software is used, which enables fast and easy creation of the control code. Different control methods are evaluated through the printing of simple walls, and the printing accuracy is evaluated by printing small shell objects. As the results show, the interpass temperature control allows small objects to be printed at near-net shape with a deviation of $2 \%$, which means that successful printing of 3D shapes can be achieved without trial and error approach.
\end{abstract}

Keywords Wire arc additive manufacturing $\cdot$ Interpass temperature control $\cdot$ Small objects $\cdot$ Near-net shape $\cdot$ Forced cooling

\section{Introduction}

Technical improvements, low investment costs and the availability of many open-source solutions have led to a widespread use of additive manufacturing technology with polymer-based materials [1], and an FDM (fused deposition modelling) printer is now an invaluable part of many workshops. However, there is no alternative that allows for affordable and reliable additive manufacturing of metal components. Due to high deposition rates, low cost of the filler material,

Drago Bračun

drago.bracun@fs.uni-lj.si

Nejc Kozamernik

nejc.kozamernik@fs.uni-lj.si

Damjan Klobčar

damjan.klobcar@fs.uni-lj.si

1 Faculty of Mechanical Engineering, University of Ljubljana, Aškerčeva cesta 6, SI-1000 Ljubljana, Slovenia good structural integrity and relatively low equipment cost, many studies have been investigating the implications of wire arc additive manufacturing (WAAM) for near-net-shape manufacturing of large metal components [2]. WAAM is a directed energy deposition process that uses an electric arc as a heat source to melt a metal filler wire [3]. The disadvantage of WAAM is its relatively low part accuracy due to thicker layers, poor surface finish and challenges associated with excessive heat input, such as residual stresses and shape distortion [4]. Excessive heat accumulation is a particularly important aspect, since an increased interpass temperature causes delayed solidification of the melt pool, resulting in a reduced deposit height and increased width [5]. This is an undesirable property in an additive manufacturing process, which requires the geometry of the deposition to be as close to the net shape as possible.

Many investigations have already been carried out which show the importance of interpass temperature management in WAAM. Montevecchi et al. [6] used a finite element-based technique to predict the required dwell time between layers to maintain a constant interpass temperature. Spencer et al. [7] 
were among the first to use a pyrometer to measure and control interpass temperature when producing simple objects from mild steel. They showed that a higher interpass temperature leads to increased surface waviness, while a lower interpass temperature leads to reduced productivity due to longer dwell times between successive layers. Yang et al. [8] performed a thermal analysis for thin walls made of low carbon steel using infrared thermography. They found that longer interlayer dwell times lead to a decreased mean temperature of the part and a smaller high temperature area, while the temperature gradient and the cooling rate of the deposited part increased, resulting in improved surface quality and a reduction in total height difference. Using numerical simulations and single-layer mild steel experiments, Zhao et al. [9] have shown that the magnitude of residual stresses could be reduced by increasing the dwell times and thus lowering the interpass temperature. The interpass temperature also has a major effect when producing objects from other materials than steel. Derekar et al. [10] have argued that a higher interpass temperature is even desired when producing aluminium alloy components, as it leads to reduced porosity. Wu et al. [11] investigated the effects of the interpass temperature and forced interpass cooling using $\mathrm{CO}_{2}$ on Ti6Al4V alloy components. They reported better surface finish and increased tensile strength at lower interpass temperatures $\left(100{ }^{\circ} \mathrm{C}\right.$ or less). Henckell et al. [12] also investigated the effects of interpass cooling during a continuous build-up process of rotational objects from mild steel. They experimented with different positions of the cooling gas nozzles and several cooling gases. Their forced-cooling experiments resulted in higher productivity and improved object geometry, a refined microstructure and homogeneous hardness across all layers, with the best results achieved with a gas mixture of nitrogen with 5\% hydrogen. Other thermal management approaches have also been investigated. Da Silva et al. [13] examined the WAAM of aluminium alloy A15Mg using the CMT process. The object was printed inside a work tank filled with water and the water level rose when the metal layers were deposited. The study reported improved quality of the deposited part with little or no significant effect on porosity and tensile mechanical properties. At the same time the build-up time was reduced by more than a half. Reisgen et al. [14] compared water bath cooling, high-pressure air cooling and aerosol cooling of the structural steel deposit using the GMA process. They found that the water bath cooling has the highest cooling effect although it makes the manipulation of the workpiece more difficult and constrains the degrees of freedom of the manufacturing process. The global high-pressure air cooling was the second most effective method of deposit cooling although, admittedly, it can only be applied when the deposition arc is turned off. The proposed aerosol cooling method could be applied in situ during the deposition process, but was not as effective, so the researchers proposed a combination of high- pressure air cooling and aerosol cooling as an efficient strategy of heat management. Different cooling strategies also affect the deposition cooling rates, i.e., $t_{8 / 5}$ cooling times, and, consequently, the microstructure and hardness of the deposited layers. The average hardness of $179 \mathrm{HV}, 196 \mathrm{HV}$ and 232 HV (reference, aerosol, water bath) was obtained, while the maximal hardness difference between the cooling regimes was up to $120 \mathrm{HV}$ (140-260 HV). Montevecchi et al. [15] proposed a cooling system where a coolant hose is attached to the welding nozzle and conveys the air jet on the deposited surface a few layers below the point of the deposition. The effectiveness of their method was assessed using a finite element thermal model of the WAAM of structural steel walls. However, the effectiveness of the proposed system was not evaluated experimentally and might not even constitute a viable solution, since cooling with high-pressure air during the deposition process, proposed by Montevecchi et al., could disturb the shielding gas atmosphere and lead to porosity problems.

In typical WAAM systems, industrial robot arms are used to move the deposition torch, which is suitable for the production of large parts and for achieving arbitrary orientation of the torch. However, an industrial robot constitutes a significant part of the investment cost of the WAAM system, and in terms of programming and online process control, it increases the complexity and limits the use of the system, e.g. by integrating interpass temperature control and cooling. This becomes apparent when the system with interpass cooling has an offset between the cooling nozzle and the deposition torch, which places additional demands on programming and system control during cooling. As an alternative to the industrial robot, Prado-Cerqueira et al. [16] developed a WAAM system by integrating a CNC milling machine and Cold Metal Transfer (CMT) welding equipment. One of the advantages mentioned was the possibility to implement milling to machine the surface of the part after the additive process. This possibility has already been investigated by Song et al. [17]. They proposed a hybrid approach called "3D welding and milling", which means that after depositing each layer, they milled the deposit to the desired thickness. When the deposition and face milling were completed, the same set-up was used for surface finishing of the product. This approach allowed them to produce functional injection moulds from which up to 100 polypropylene parts could be formed [18]. If the same CNC system is used for WAAM and for milling, it must be more rigid and accurate than if used for WAAM only, which makes it more expensive. As also discussed by Manogharan et al. [19], a separate milling station for surface machining is usually more economical, since a relatively small percentage of the production time is used for the machining process compared with the additive manufacturing process. Nagamatsu et al. [20] developed a cooperative system for WAAM and machining. In order to prevent overheating, printing was done in a 
water tank with manually adjustable water levels. The 3D shape of the printed object was measured by photogrammetry. The measurements were used to verify whether the target shape was enclosed within a printed object and to modify the work origin for surface machining on a separate machining centre. With the aim of developing a low-cost system, Anzalone et al. [21] developed a \$2000 open-source WAAM 3D printer on the basis of Rostock, a Deltabot RepRap with promising results. However, none of the above systems, which are based on three-axis machines, included the interpass temperature control, which is crucial for achieving the desired geometry of the deposition, especially since these systems could only produce smaller parts where heat accumulation is high due to the short time that passes between depositing successive layers.

One of the benefits of using a three-axis positioning system is the ability to use path-generation software dedicated to FDM printers, with some modifications required to make them suitable for WAAM. Nilsiam et al. [22] introduced a WAAM slicer for welding path generation by modifying an open-source Cura slicer. Their solution included a certain degree of WAAM-related path optimisation; however, they encountered the problem of heat accumulation during case studies, since their system also did not include interpass temperature control or cooling. Others dedicated their research strictly to WAAM dedicated path-planning algorithms. Dwivedi and Kovacevic [23] proposed an automated torch path planning method for WAAM with the goal of performing continuous deposition with minimum human intervention. Y. Li et al. [24] used an artificial neural network to predict the offset distance of deposit and implemented a reasoning algorithm to calculate the optimal distance between the centres of the adjacent deposition paths for multi-layer multi-bead parts. Sharp corners are another challenge for WAAM. In order to achieve uniform deposit morphology along the toolpath with fixed deposition parameters, constant travel speed has to be maintained. However, in practice this becomes impossible when encountering sharp corners, since the positioning system has to slow down so that the centripetal acceleration stays below the allowed value. Consequently, excessive fillings occur, leading to improper deposit geometry or even to disruption of the deposition process if the accumulated error becomes too large. F. Li et al. [25] solved the issue by employing a control scheme which divided the planned toolpath into several segments (depending on whether they contained sharp corners or not) and then selected the allowable travel speed and appropriate wire-feed rate for each segment, according to a preestablished process model.

In an attempt to find a solution similar to the FDM 3D printers, this paper proposes a three-axis CNC-based WAAM system. The system should be cost-efficient, easy to programme and operate, but nevertheless versatile. Complex shapes should be quick and easy to produce, with predictable results. This could be a basis for an inexpensive, commercially available WAAM system or simply a great tool for further research of the process. The biggest challenge that needs to be overcome is the shape distortion caused by extreme heat input and variable heat dissipation through the growing walls. The residual heat that builds up in the growing walls causes delayed solidification during the deposition of layers high from the base. The reduced layer height and greater deposition width mean that the printed form may begin to deviate from its net shape. To resolve this problem, the present study relies on integration of the $\mathrm{CNC}$ motion, temperature measurement and cooling systems, as well as cladding control strategies to minimize shape distortion. In most of the literature employing interpass temperature control or forced cooling, the investigated system or control strategies are not described in detail; consequently, this implementation is presented so that it can be reproduced relatively easily by others, using open-source software. A case study will be conducted to evaluate the effectiveness of the proposed WAAM system and control strategies.

\section{The WAAM system}

A conceptual diagram of a WAAM system with an integrated closed loop layer interpass temperature control and cooling system is shown in Fig. 1 and its design in Fig. 2. The concept of the system is similar to that of FDM 3D printers. A threeaxis $\mathrm{CNC}$ machine is used as a positioning system. The work table moves in all three axes $(X, 165 \mathrm{~mm} ; Y, 180 \mathrm{~mm} Z Z, 220$ $\mathrm{mm}$ ) under the fixed deposition torch. The machine is equipped with a protective box that protects the environment from UV radiation and spatter during deposition. The base table under the worktable is water-cooled and electrically insulated from the rest of the system. A Daihen Welbee Inverter P500L is used as the deposition power source. It has an integrated coolant pump with tubing routed through the wire feeder (CM-7402-D) to the water-cooled base table. The system is controlled by an open-source LinuxCNC motion controller, which is responsible for the synchronous operation of all systems. It accepts G-code inputs and controls the three-axis positioning system with a control signal vector $\left\{U_{C}\right\}$. The CNC motion controller also communicates with the deposition power supply via the control signal vector $\left\{V_{C}\right\}$, which turns the deposition process on and off and provides feedback to the $\mathrm{CNC}$ controller when the deposition current is detected and the electric arc is ignited. Arc voltage and deposition current are set via the welding tasks on the power supply. Temperature control is done by measuring the weld interpass temperature, and when it is lower or equal to the reference temperature $T_{\mathrm{REF}}$, a new layer is added. The desired $T_{\mathrm{REF}}$ for stable deposit was obtained experimentally. Similar to the approach Nilsiam et al. [22] have taken, open-source 


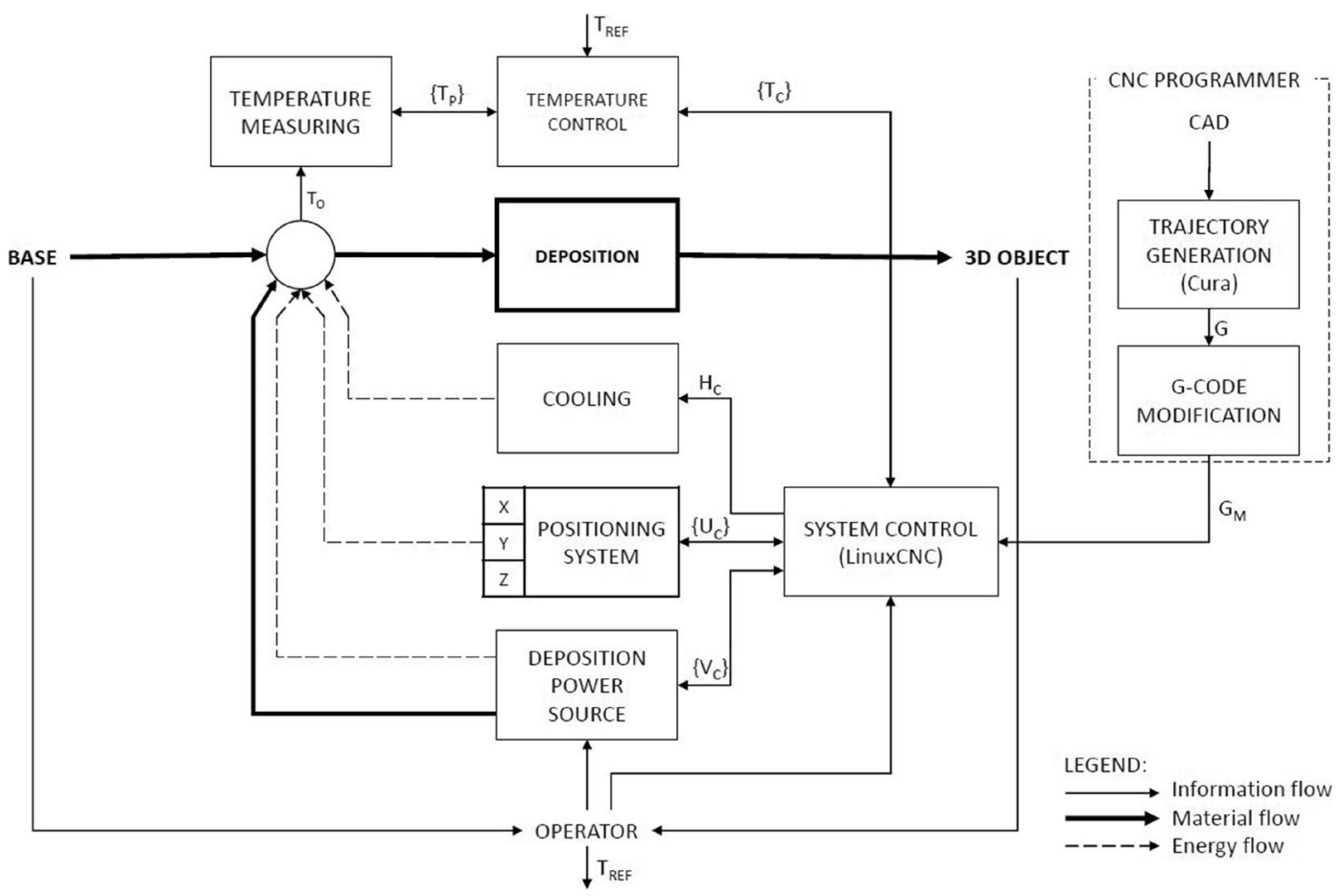

Fig. 1 WAAM system employing interpass temperature control

Cura 3D slicer [26] is used to create the layer path from the CAD model and the output G-code for motion control. A custom script is used on the output G-code to add correct subroutines, inputs and control outputs $\left\{T_{c}, H_{c}, V_{c}\right\}$ for temperature control, cooling and deposition. Layer height and width are determined experimentally and set in the Cura 3D slicer. A useful feature of the slicer is the random $\mathrm{Z}$ seam alignment. With this option, the machine starts and finishes each layer at a random position, resulting in less noticeable seam starts and ends.

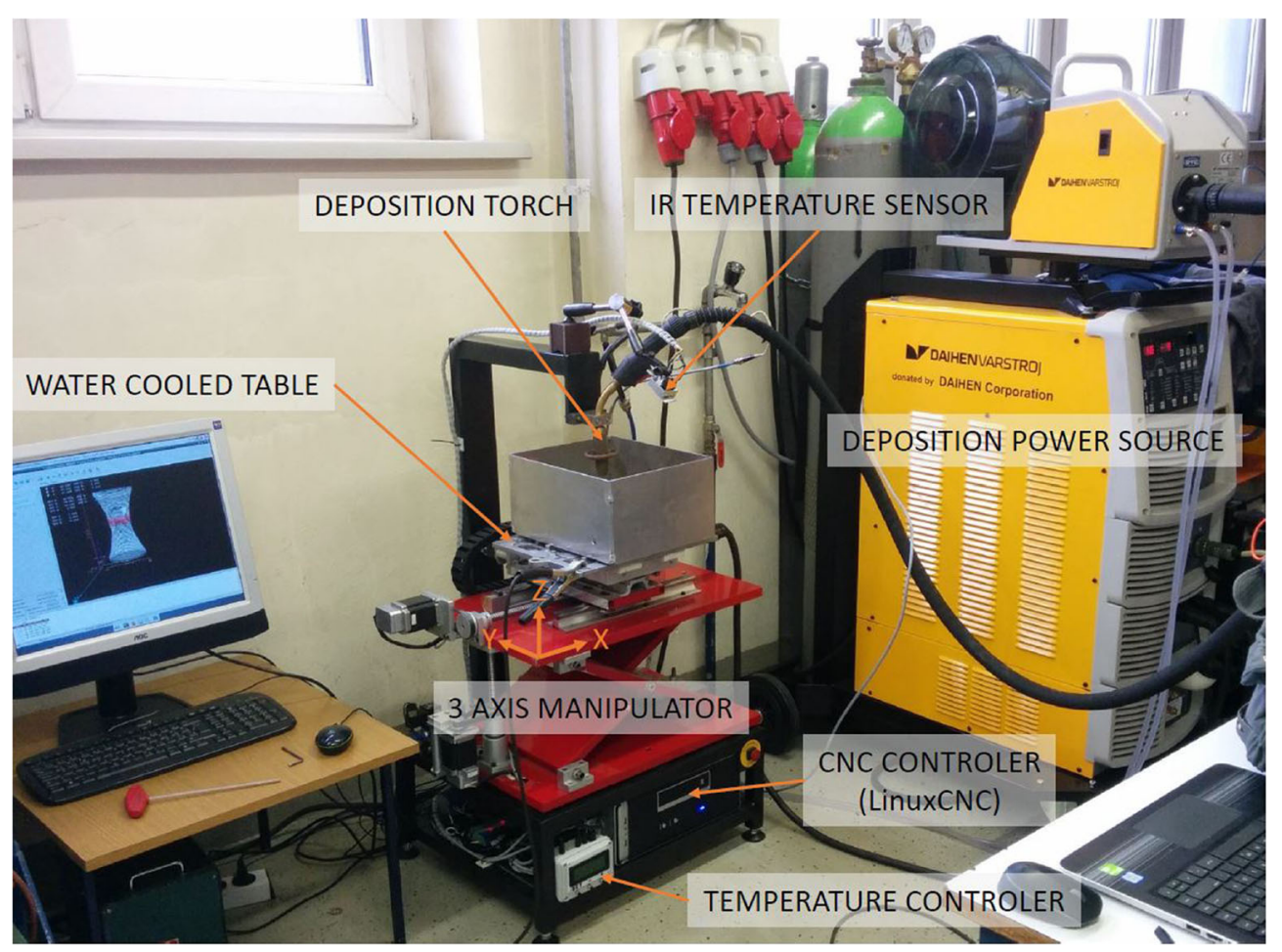

Fig. 2 A three-axis CNC WAAM system 


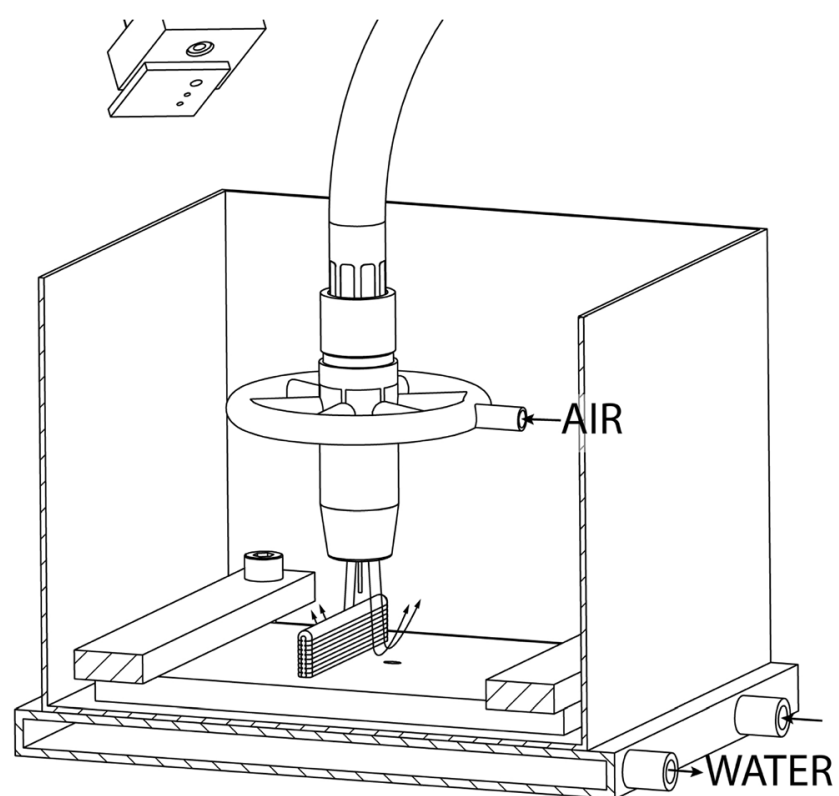

Fig. 3 Compressed air cooling through the deposition nozzle and liquidcooled base table

\subsection{The cooling system}

Deposits are cooled using high-pressure air as shown in Fig. 3. An additional ring inlet for high-pressure air is added to the deposition nozzle. Compressed air flows through the deposition nozzle and cools the deposit directly below the nozzle. The CNC machine repeats the path of the last layer several times with air cooling turned on until the layer temperature along the path is lower than specified. Since the welding arc is turned off during cooling, the cooling-off period is longer than with water baths. Nevertheless, air cooling is safer, adapts to the actual topography of the deposit and is still more effective than blowing in compressed air or aerosols from some ex situ fixed point. In addition to air cooling, the water-cooled base table of the protective box extracts the heat from the base table and protects the $\mathrm{CNC}$ positioning system from overheating.
The base table cooling is realised using the water cooling system dedicated to the deposition torch.

A combination of high-pressure air cooling and a watercooled base table is chosen to avoid any issues normally associated with electrical safety and maintenance requirements of a water cooling system, as investigated in [14]. Owing to longer cooling times $\left(t_{8 / 5}\right)$, the proposed high-pressure air cooling allows for fewer changes in microstructure and hardness. On the other hand, shorter production times can be obtained if water bath cooling is used [13].

\subsection{Interpass temperature measurement and control}

The interpass temperature is measured using a Melexis IR pyrometer (MLX90614ESF-BCI-000-TU). It is a low-cost temperature sensor with a $5^{\circ}$ field of view (FOV), which allows temperature measurements to be taken within a relatively small area from a safe distance (see Fig. 4 a and b). The pyrometer is rigidly connected to the deposition nozzle and aligned with an adjustable arm positioned directly into the area below the nozzle. The deposition nozzle, pyrometer and cooling system thus form a compact deposition unit which is rigidly attached to the supporting structure. The printing object is moved relative to the deposition unit by a CNC system. The advantage of such compact design of the deposition unit is that in the case of the robot-supported WAAM system, it can be used as the end effector of an industrial robot. The pyrometer is also equipped with a protection hatch which is closed during the deposition process and open during the measuring and cooling cycles. The microcontroller ATmega328p is used for temperature control (Fig. 4c). The operator sets the desired interpass temperature $T_{\mathrm{REF}}$ and material emissivity $\varepsilon$ on the temperature controller. The temperature controller inspects whether the measured temperature along the path is below the reference temperature and communicates this information to the LinuxCNC controller via a signal vector $\left\{T_{C}\right\}$.

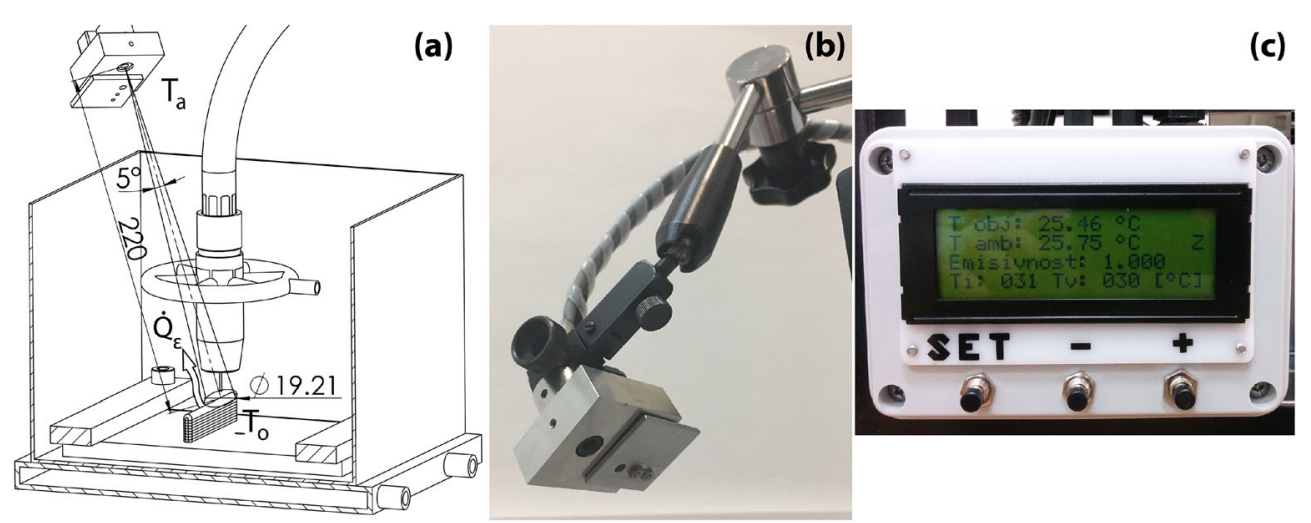

Fig. 4 a Orientation and field of view of the pyrometer, $\mathbf{b}$ installation and protection of the pyrometer, $\mathbf{c}$ temperature controller 


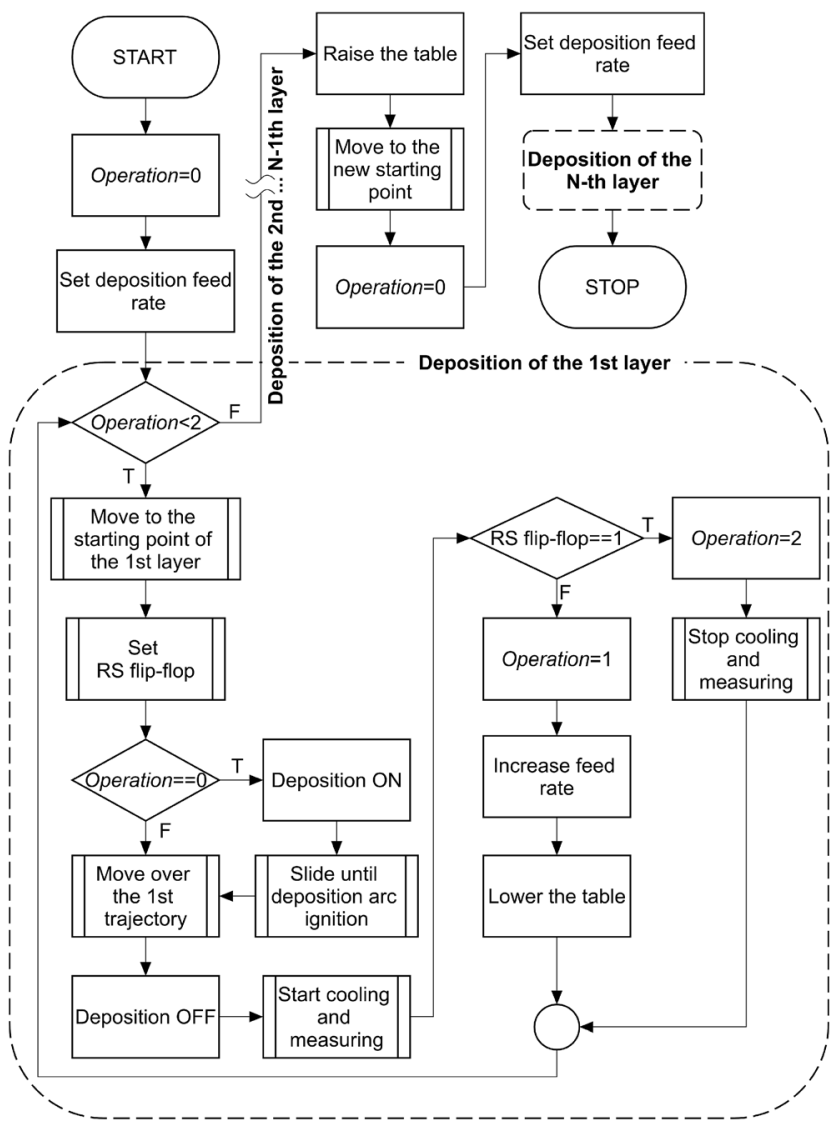

Fig. 5 Deposition control flow chart

\section{Layer cladding control}

The open-source software Cura for FDM 3D printing is used to slice the CAD model. The generated G-code must be further modified using a user-defined script, to add control signals and sub-programmes, e.g. sliding until arc ignition and filling. Special features inherent to the arc deposition, as, for example, discussed in [27], are not taken into account. Figure 5 shows a simplified flowchart of the CNC control programme for deposition. G-code global parameter operation defines whether the deposition or cooling should be done through a loop of the current layer. If the value is 0 , the layer has not yet been deposited and the machine should start deposition before moving over the programmed trajectory for the first time (G1 movement). The machine moves to the origin of a new layer. The deposition current is turned on, and the machine slides the wire against the base material until the electric arc is ignited. This ensures better arc ignition and prevents the wire from sticking. When the electric arc is ignited, the machine moves at a deposition travel speed along the programmed path.

After a certain layer has been deposited and the deposition has been stopped, air cooling is switched on and the protective hatch of the IR pyrometer is opened. The table is lowered by $5 \mathrm{~mm}$ to prevent collisions between the deposited layer and the free end of the wire. The travel speed is increased, and the operation parameter is set to 1 , indicating that the cooling and measuring cycle has started. The machine repeatedly moves over the last deposited layer until the temperature along the entire layer is below the desired interpass temperature. This is achieved with the RS (Reset/Set) flip-flop in the hardware abstraction layer of Linux CNC controller. The CNC controller sets the RS flip-flop to high at the beginning of each measuring cycle and checks its status at the end of each cycle. If the interpass temperature exceeds the desired temperature $T_{\mathrm{REF}}$ at any point of the trajectory, the temperature controller resets the RS flip-flop. When the deposit reaches the desired temperature, the air cooling is stopped, and the pyrometer's protective hatch is closed. The parameter operation is set to 2 , indicating that the layer is cooled enough and the machine can exit the loop and start a new layer deposition. The operation parameter is set back to 0 , and the machine moves to a new (randomly positioned) origin and repeats the whole process again until the part is finished.

An example of the deposition control flow for production of a simple wall is shown in Fig. 6. Each successive layer is deposited in the opposite direction to the previously formed one. The horizontal axis marks the distance travelled along the deposition path, and the vertical axis marks the time. Blackdotted lines mark different $Z$ levels (the distance between the machine table and the deposition torch). The layer height is marked with the symbol $\Delta \mathrm{Z}$. Red lines mark the path travelled during the deposition, and blue lines mark the path during the measuring and cooling cycles. Green lines indicate the wire sliding against the base material until the deposition arc is ignited. During the deposition, the operation parameter takes the value of 0 . When the measuring and cooling cycle starts,

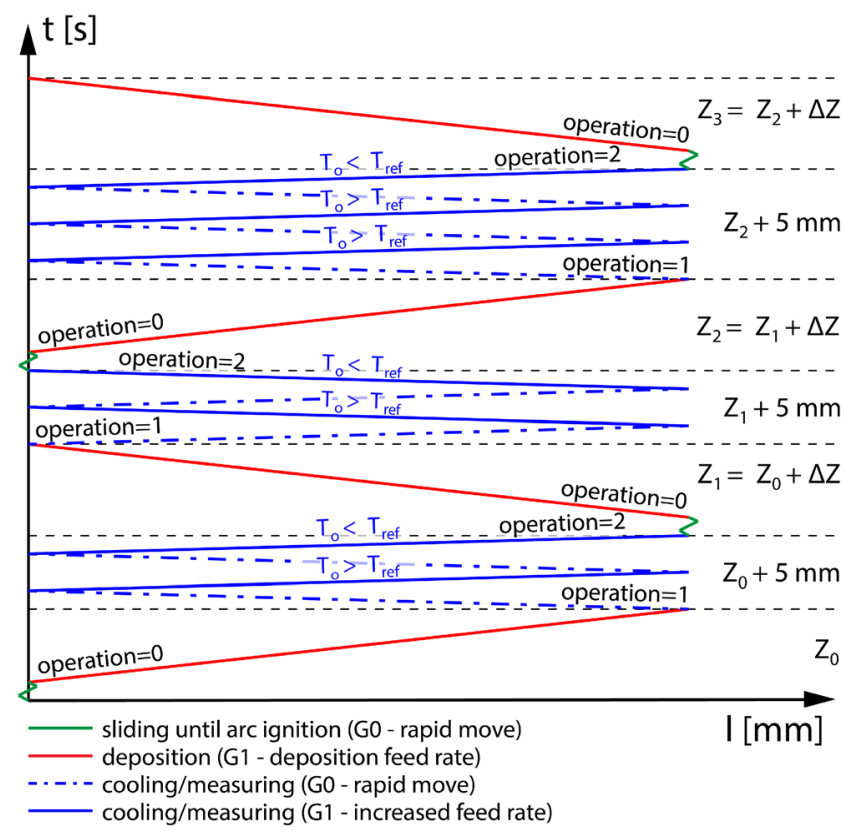

Fig. 6 An example of the deposition control flow 


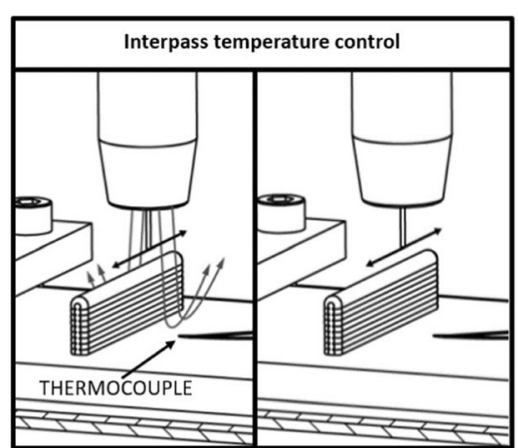

(a) COOLING

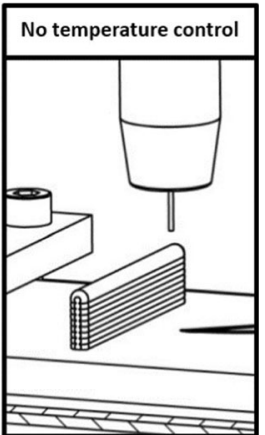

(c) DELAYS

Fig. 7 Control methods employed: (a) interpass temperature control and forced air cooling, (b) interpass temperature control without forced air cooling and (c) with delays only

the operation parameter is set to 1 until the temperature on the entire path is below the reference temperature. When the temperature is sufficiently low, the operation parameter is set to 2 , indicating the deposition of the next layer can begin.

\section{Experiments}

The effects of the proposed interpass temperature control and forced cooling on the quality of the prints were evaluated by comparing simple walls produced with different control methods. The reference interpass temperature of $150{ }^{\circ} \mathrm{C}$ was selected based on the visual appearance of the walls in the preliminary study, where the interpass temperature varied from 50 to $250{ }^{\circ} \mathrm{C}$, and the research reported by Spencer et al. [7], where the interpass temperature varied from 120 to $300{ }^{\circ} \mathrm{C}$. The authors also proposed the interpass temperature range from 120 to $180{ }^{\circ} \mathrm{C}$ for deposition of the SG2 filler material. During the experiments, 16-layer, 70-mm-long walls were deposited in the middle of a base plate made of 5-mmthick mild steel measuring $100 \times 200 \mathrm{~mm}$. A thermocouple was used to measure the temperature of the base plate, while the interpass temperature was measured with an IR pyrometer. In all cases, the base plate was cooled using the integrated cooling system of the power source. A mild steel filler wire G3Sil with a diameter of $1.2 \mathrm{~mm}$ was used. All walls were produced using $82 \% \mathrm{Ar}$ and $18 \% \mathrm{CO}_{2}$ mixture as shielding gas with a flow rate of $15 \mathrm{~L} / \mathrm{min}$, spatter-free deposition programme (66 A, $14.4 \mathrm{~V}$ ), travel speed of $300 \mathrm{~mm} / \mathrm{min}$ and the initial base plate to the deposition nozzle distance of $15 \mathrm{~mm}$.

Three different control methods were tested (shown in Fig. 7):

- In the first method (a-cooling), interpass temperature control and forced air cooling are used during the temperature measurement. The reference weld interpass temperature is set to $T_{\mathrm{REF}}=150^{\circ} \mathrm{C}$, and the deposition process is as shown in Fig. 6.

- In the second method ( $b$ - without cooling), interpass temperature control is implemented, but without forced air cooling. The reference interpass temperature is set to $T_{\mathrm{REF}}=150{ }^{\circ} \mathrm{C}$, and the deposition process is as shown in Fig. 6.

- In the third method (c - delays), interpass temperature control is switched off, and no forced air cooling is used. The inter-layer dwell time is set to a constant value of $36 \mathrm{~s}$ for all layers. The dwell time value has been chosen based on the average time required to produce the part with the first control method and with the aim of achieving the same production time when applying time delays or cooling. The interpass temperature is still measured and stored, but it is only measured at the end of the wall, where the deposition stopped.

During all tests, the temperature of the base plate was measured using K-type thermocouple. The produced walls were sectioned in the vertical direction to obtain macrosections for analysing their microstructure. The remaining walls were machined and ground to obtain flat surfaces from which miniature tensile specimens (Fig. 14a) were sectioned using a water jet. The specimens for microstructure analysis were ground, polished and etched using a $2 \%$ Nital reagent. Optical microscopy was done using a digital microscope Keyence VHX-6000. The tensile tests were conducted using a Zwick Z250 tensile testing machine. To investigate shape distortions with and without the interpass temperature control, multiple shell objects were printed and compared with the CAD model of the desired 3D object. The proposed system is capable of storing the deposition parameters and interpass temperatures measured during the deposition process. These can be used for further studies of the deposition process and possible defects or to create a database that allows a quick estimation of the required interpass temperature and deposition parameters for specific layer dimensions.

\section{Results and discussion}

\subsection{Temperatures, production times and shape}

Figure 8 shows the interpass temperatures measured between the layers (a-1, b-1, c-1) and the resulting walls (a-2, b-2, c-2) using an IR pyrometer. When the measured temperature is close to room temperature, the protective hatch is closed, and deposition is performed. Sections that display temperature spikes are recorded during the cooling cycles. The green line on each diagram connects the interpass temperatures just before the addition of a new layer (shown separately in the bar graph in Fig. 12). The results show that when using 
temperature control, deposition is carried out at a constant interpass temperature of $150{ }^{\circ} \mathrm{C}$ (Fig. 8 a-1 and a-2). When deposition is carried out with constant delays, the interpass temperature rises continuously to over $200{ }^{\circ} \mathrm{C}$ due to insufficient delay times (Fig. 8 c-1).

Print time is analysed using interpass temperature diagrams shown in Fig. 8. The wall printed with constant delays between passes without applying forced air cooling (c-2) is intentionally built in the same total production time as the wall for which temperature control and forced air cooling (a-2) were implemented in order to show how overheating affects shape distortion. The constant delay time $t_{\mathrm{L}}=36 \mathrm{~s}$ for $(\mathrm{c}-2)$ wall is calculated from production times of the (a-2) wall as $t_{\mathrm{L}}=\left(t_{\mathrm{p}}-t_{\mathrm{d}}\right) / N$, where $t_{\mathrm{p}}$ equals total production time of (a-2), $t_{\mathrm{d}}$ equals total deposition time of (a-2) and $N$ number of layers. Cooling consumes a considerable amount of production time. This can be improved by parallel printing of several parts and using effective cooling methods, e.g. water bath immersion or forced air cooling, as demonstrated in our case. For demonstration, the (b-2) wall is produced with the layer interpass temperature control but without forced air cooling. Production time is more than $30 \%$ longer in comparison with the forced air cooling as demonstrated in (a2 ). The cooling time for each layer is also analysed in more detail in the bar chart shown in Fig. 9. The diagram shows the exact additional cooling time required for layers produced without forced air cooling compared with layers where forced cooling was applied. The cooling time increases for the higher layers in the wall, because heat transfer to the base material is slower and heat convection to air takes longer to cool the wall. The temperature of the base plate can be observed in Fig. 10. Considerably, more heat is accumulated in the base when no air cooling is used, regardless of interpass temperature control. This shows that a lot of heat is dissipated by convection due to forced air cooling. The effect is even more apparent when cooling layers higher in the wall. Thermal conduction to the base material is slower, yet the surface area of the wall is larger, improving heat convection. In addition, a comparison between Fig. 9 and Fig. 10 shows that the base plate temperature depends on the heat input and cooling of the product. Quicker deposition, with shorter delays, led to a rise in base plate temperature until a steady state is reached at approx. $200{ }^{\circ} \mathrm{C}$. When using temperature control without forced air cooling, production time is longer, and the base plate reaches a steady-state temperature at around $150{ }^{\circ} \mathrm{C}$. This means that similar quantity of heat is transferred throughout the base plate and throughout the walls. When additional forced air cooling is used together with temperature control, more heat is transferred to the air and less to the base plate. Consequentially, the base plate temperature drops to $100{ }^{\circ} \mathrm{C}$ and lower, as the wall rises.

To analyse the effects of different control methods on shape distortions, the walls were cut to $20 \mathrm{~mm}$ from the end where deposition was stable. These samples are sequentially ground using different grinding papers, polished and etched with $2 \%$ Nital reagent to expose their macrostructure. Figure 11 shows an example of the final cross sections of

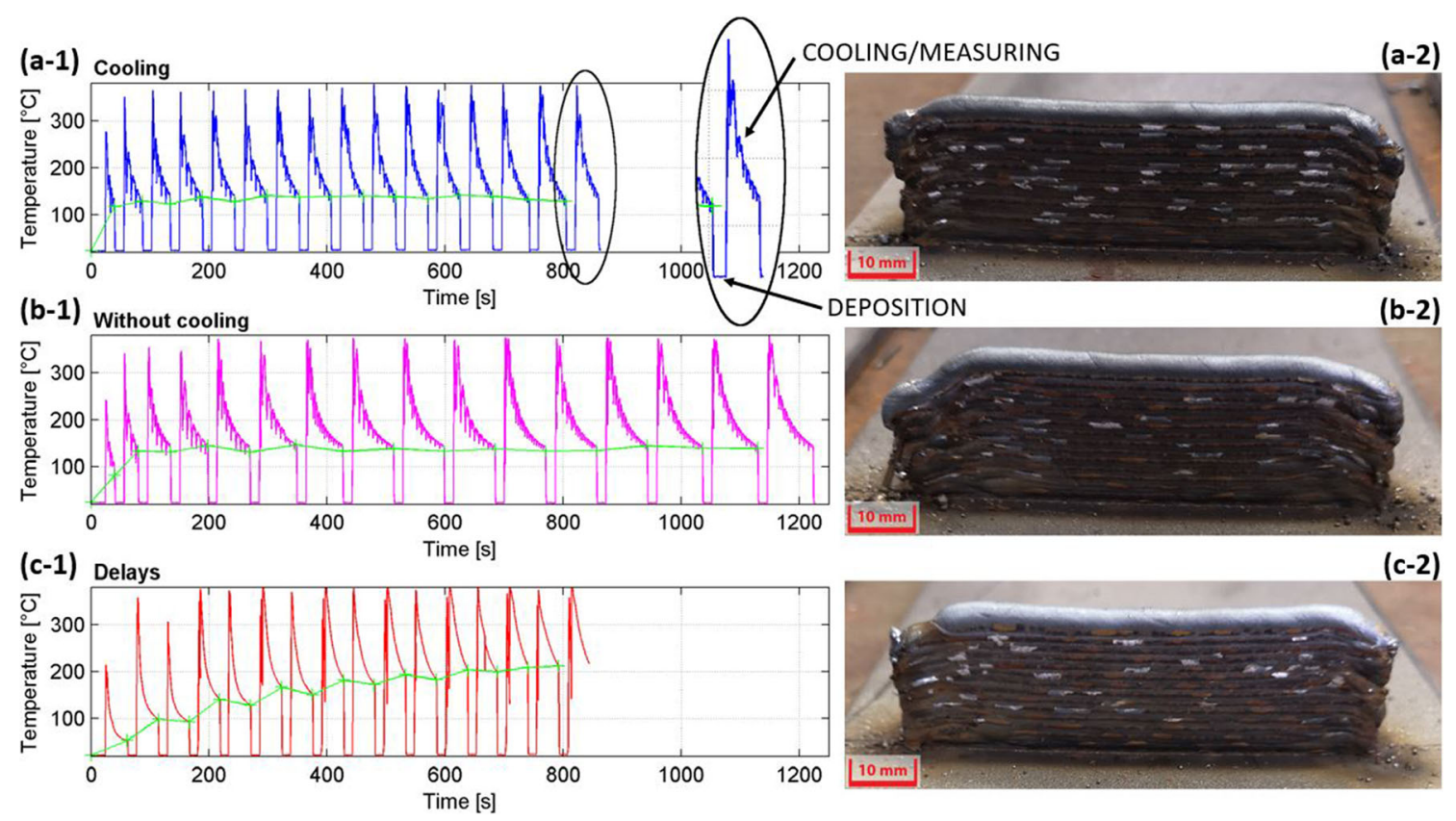

Fig. 8 Interpass temperatures (column 1) and walls (column 2) manufactured using (a) temperature control and forced air cooling, (b) temperature control without forced air cooling, and (c) constant time delays between layers without forced air cooling 


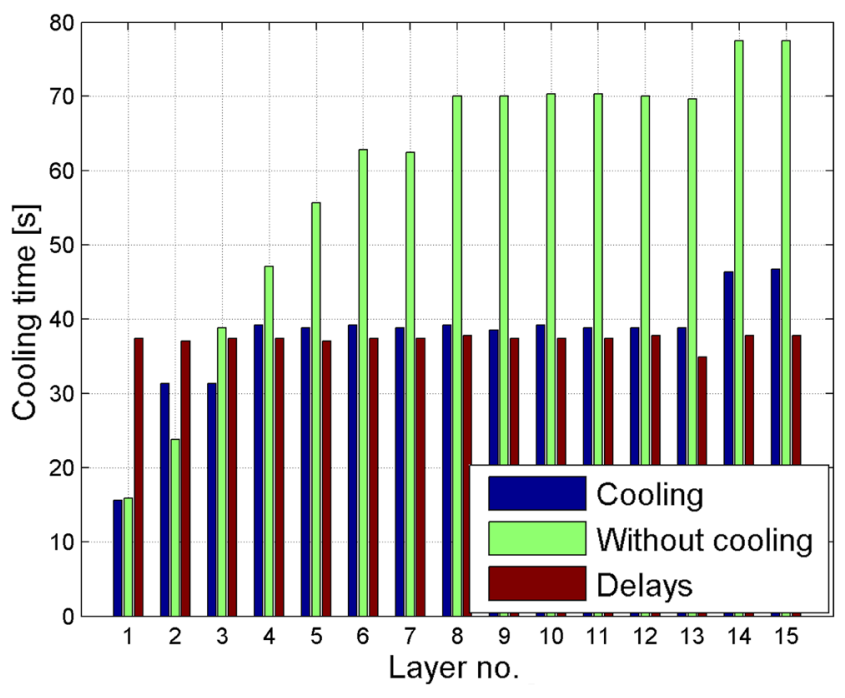

Fig. 9 Cooling time by layer

samples taken with a Keyence VHX-6000 microscope at $\times 20$ magnification. The average height $(H)$ of the walls was 23.36 $\mathrm{mm}, 23.30 \mathrm{~mm}$ and $22.9 \mathrm{~mm}$ for $H_{\mathrm{c}}, H_{\mathrm{woc}}$ and $H_{\mathrm{d}}$, respectively, and the average width $(W)$ of the walls over the top three layers being $3.68 \mathrm{~mm}, 3.71 \mathrm{~mm}$ and $3.94 \mathrm{~mm}$ for $W_{\mathrm{c}}, W_{\text {woc }}$ and $W_{d}$, respectively (in the indexes, "c" stands for temperature control with forced air cooling, "woc" means temperature control without forced air cooling and "d" means delays). It can be observed that $H_{\mathrm{d}}$ is on average $2 \%$ lower than $H_{\mathrm{c}}$. For further cross-sectional analysis, lines can be drawn through the fusion lines exposed by etching, and the height of individual layers can be approximated. A first significant offset in the layer height on the walls made with delays can be observed at the sixth layer (see yellow dotted lines) and increases with subsequent layers. These results can be correlated with the interpass temperatures (Fig. 12) measured shortly before the deposition of a new layer.

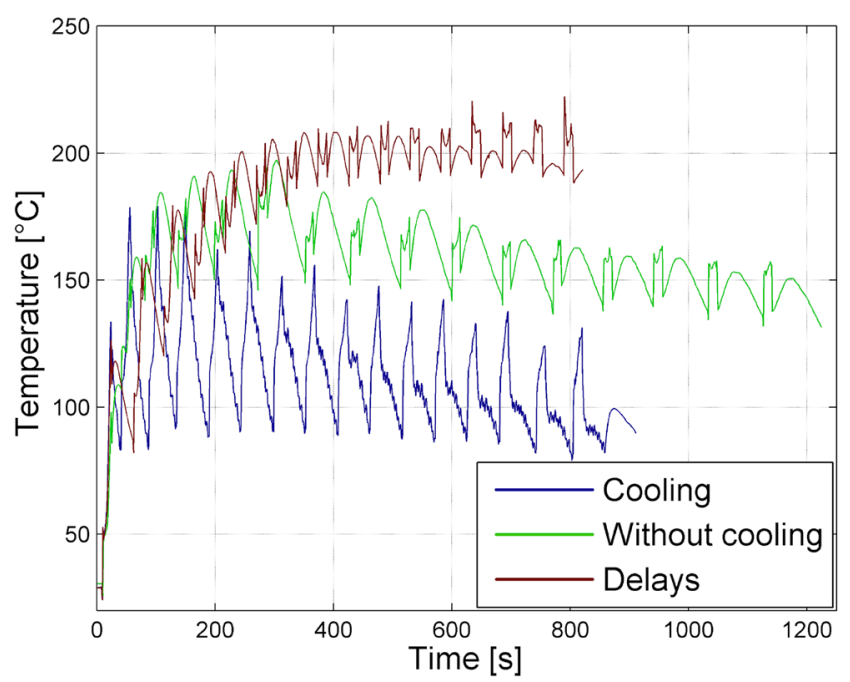

Fig. 10 Temperature of the base plate

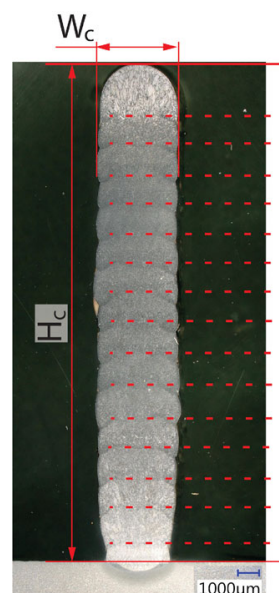

(a) COOLING

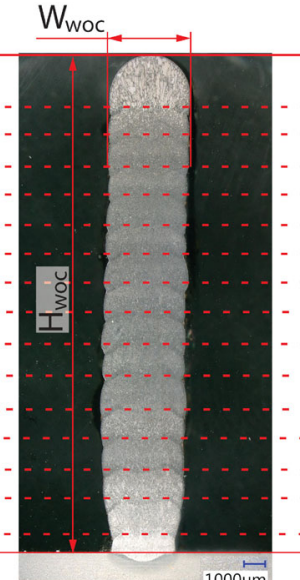

(b) WITHOUT COOLING

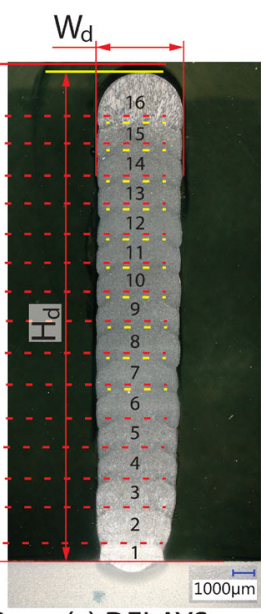

(c) DELAYS
Fig. 11 Cross sections of the walls

During the production of the wall with constant delays (Fig. 11c), the desired interpass temperature of $150^{\circ} \mathrm{C}$ was exceeded from the sixth layer onwards, and layers became lower and wider. This effect was quite small, as the delays were calculated and selected from the previous tests with temperature control in a way that the production times are similar to the production times achieved when using temperature control with cooling. If the selected delays were shorter, the difference in height and width would be more exposed.

\subsection{Microstructure and mechanical properties}

The effect of different control methods on the quality of produced walls was assessed using microstructure and tensile strength analysis in the horizontal direction. The microstructure of the walls at different heights is shown in Fig. 13. Sections a-3, b-3 and c-3 show lower wall

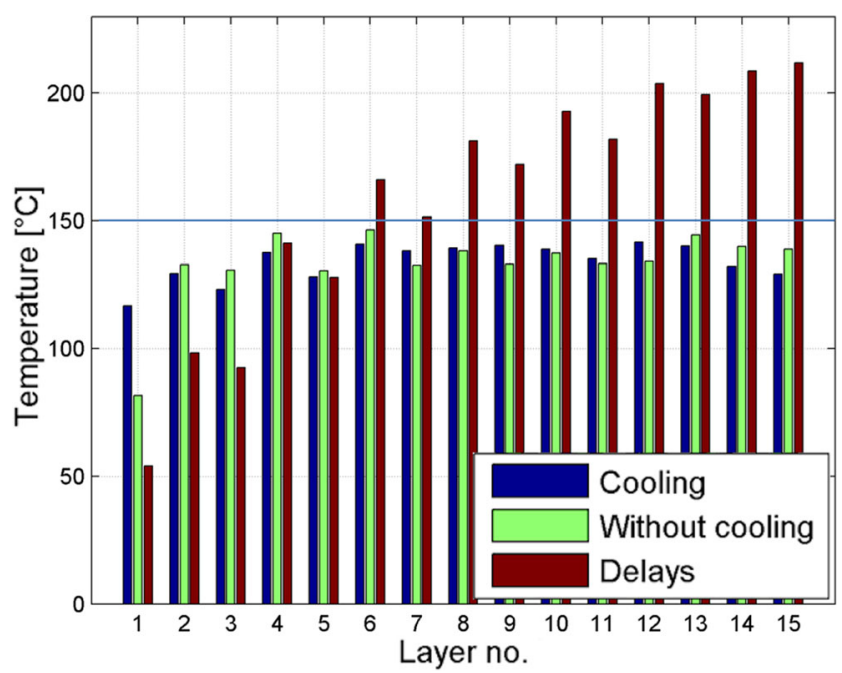

Fig. 12 Interpass temperature just before the deposition of the next layer 

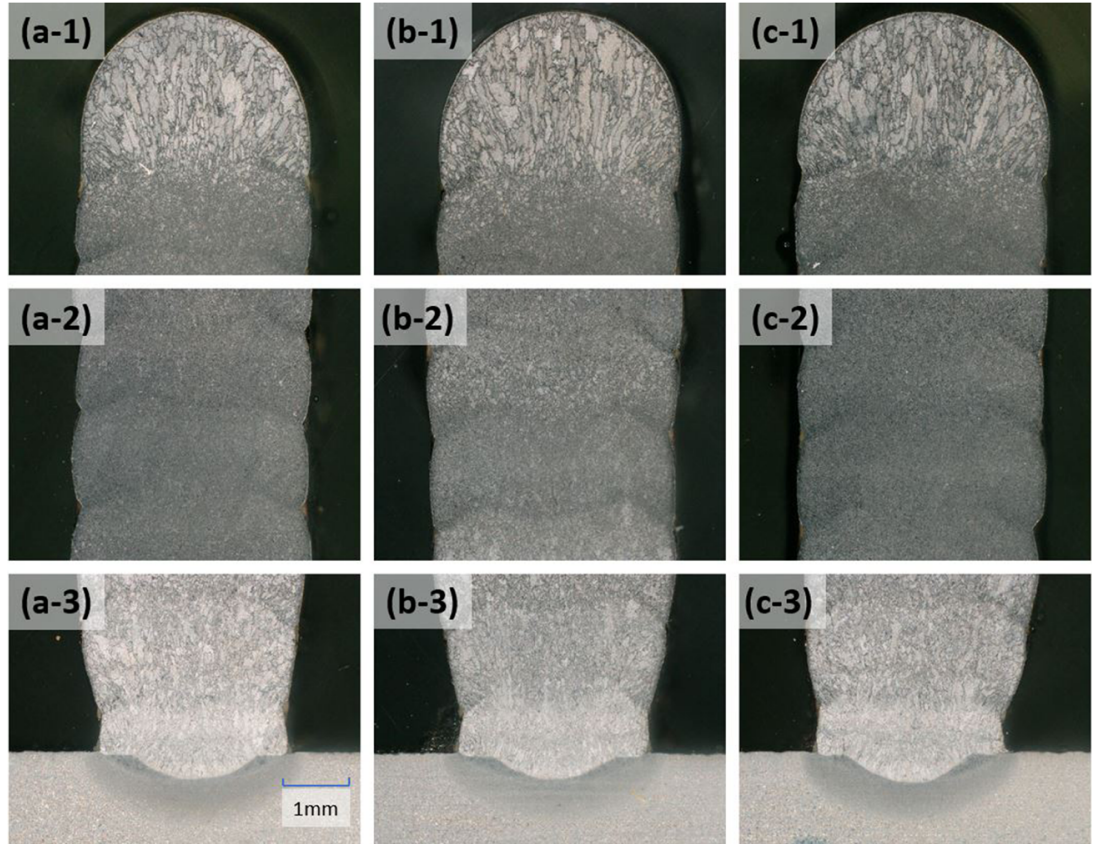

Fig. 13 Microstructure of the walls for different control methods: (a) interpass temperature control and forced air cooling, (b) interpass temperature control without forced air cooling and (c) with delays only. The cross sections are cut from (1) the last layer, (2) the middle layers and (3) the first layer

thickness and higher deposit for the first layer, due to higher heat sink to the base material. Here, slightly elongated crystal grains can be seen close to the heat-affected zone. In the middle section (Fig. 13 a-2, b-2 and c-2) a fine grain microstructure is obtained, since this material

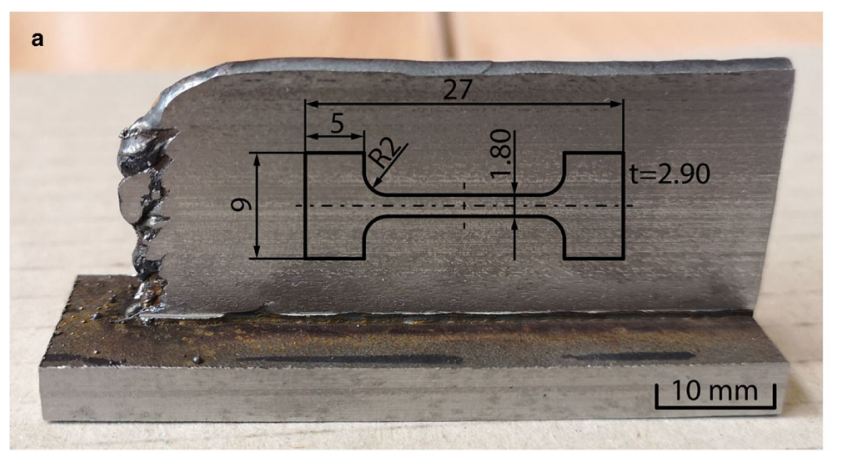

b

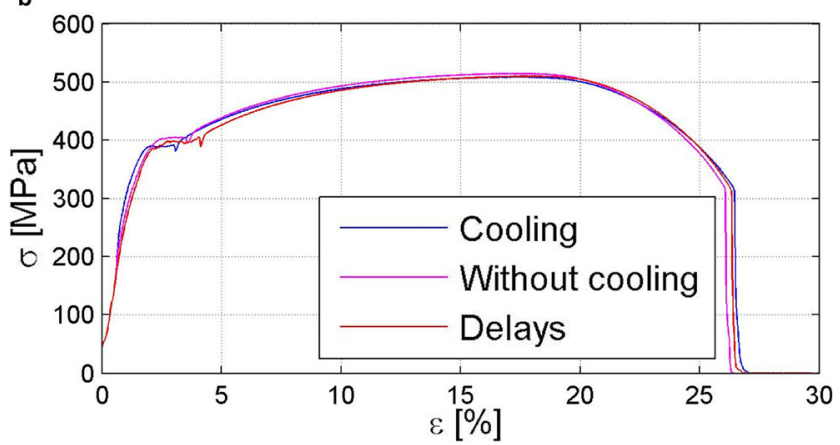

Fig. 14 a Representation of tensile test specimens and $\mathbf{b}$ static tensile test results was heated several times during the deposition of upper layers and accumulation of temperature in the walls. Fusion lines and HAZ can be noted as well. The sections $\mathrm{a}-1, \mathrm{~b}-1$ and $\mathrm{c}-1$ in Fig. 13 show the microstructure of the last deposit. Larger elongated grains are visible that grow in the direction of heat sink. All three walls display similar microstructure throughout the wall height, since similar heat input was used for depositions, and the interpass temperature, material and heat sink were similar.

The mechanical properties of the walls were tested using a static tensile test. Figure 14a shows the position, orientation and dimensions of the samples on the wall from which they were cut by water jet cutting.

The test specimens were cut and tested in the layer deposition direction using a Zwick Z250 tensile testing machine and testing speed of $2.5 \mathrm{~mm} / \mathrm{min}$. Figure $14 \mathrm{~b}$ shows the results of the tensile test for all three specimens. As expected, no significant difference in the results was found, and there was no difference in the microstructures. This can be explained by the fact that interpass temperatures did not differ significantly between the samples made using different control methods. The temperature difference was high enough to influence the deposit geometry, but not enough to make a meaningful difference in the microstructure and mechanical properties of the manufactured walls (Fig. 13). Although air was used as a cooling gas, this did not have a negative effect on the quality of the walls (Fig. 14 b), as the cooling of the object only started after the entire layer had been deposited and solidified. 
(a)

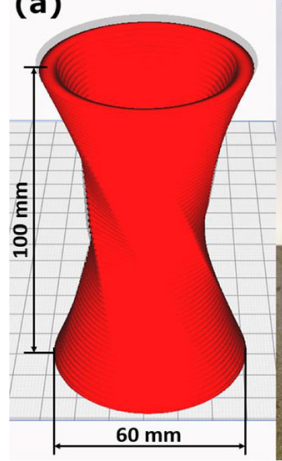

(b)

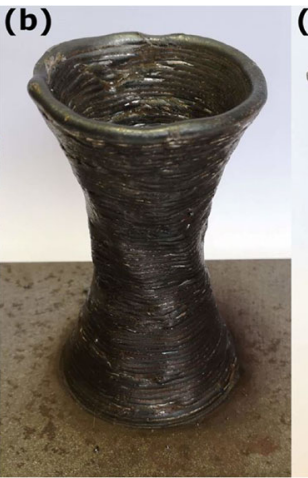

(c)

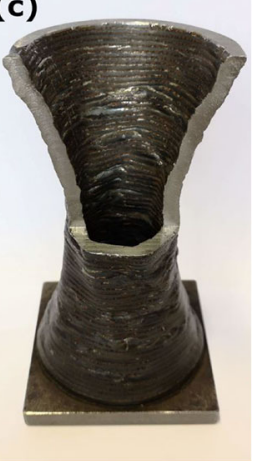

Fig. 15 a The object model in a slicer, $\mathbf{b}$ final printed object and $\mathbf{c}$ partial cross section of the same object

\subsection{Shape distortion analysis}

The shape distortion analysis was performed by comparing the shape of a printed object with its CAD model. Figure 15 a shows the object's CAD model in a slicer, Fig. $15 \mathrm{~b}$ the resulting object and Fig. $15 \mathrm{c}$ its partial cross section. The object has a circular base which transforms from a circle with a diameter of $60 \mathrm{~mm}$ into a narrower hexagonal spiral and back into a circle. The control method with interpass temperature control at $150^{\circ} \mathrm{C}$ and forced air cooling is used. The layer height of $1.53 \mathrm{~mm}$ and width of $4.7 \mathrm{~mm}$ were determined experimentally by printing simple walls. During the printing, a total of 65 layers were deposited.

The printed object was scanned with a Shining Einscan-SP 3D scanner. The resulting mesh of almost $0.7 \mathrm{M}$ vertices was used to calculate the Hausdorff distance [28] between the scan and the object CAD model. The calculated mean Hausdorff distance is $0.37 \mathrm{~mm}$, and the root mean value is $0.51 \mathrm{~mm}$. Figure 16 shows the scanned mesh coloured according to the relative distance between the printed object and its CAD model. The results show that the greatest deviation from the net shape is in the humps on the top of the object, which are caused by

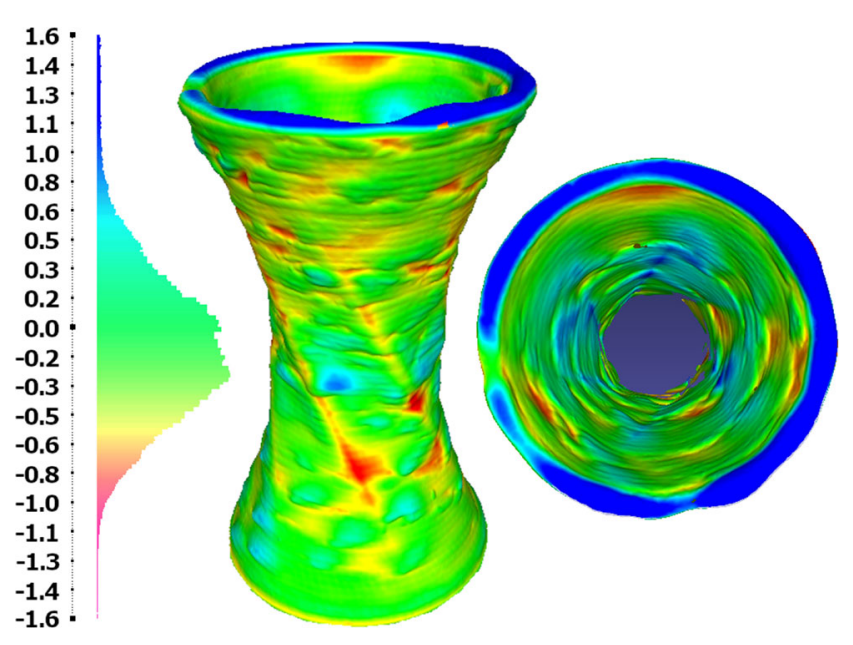

Fig. 16 Printed object and CAD model comparison

the beginning and end of the weld cladding process. The average height of the printed object is $101 \mathrm{~mm}$, which is $1 \mathrm{~mm}$ more than expected. Layer seams are still visible, even though the random Z-seam alignment feature was used in the slicer. In order to improve the result, the control strategy proposed by Xiong et al. [29] could be employed by keeping the deposition current constant and increasing deposit velocity in the arc striking area. Surface irregularities due to arc ignition could also be further reduced by using a high voltage and highfrequency system similar to GTAW machines.

Even though the forced air cooling was used, cooling still consumed a considerable amount of the printing time. In total printing lasted $1 \mathrm{~h}$ and $50 \mathrm{~min}$, of which about $1 \mathrm{~h}$ and 16 min were used for cooling (70\%). As already demonstrated by printing simple walls, the cooling time would be much longer if no forced air cooling was used, especially since this was a relatively high object compared with its diameter.

To further demonstrate the importance of interpass temperature control, two additional objects were printed without temperature control. The object shown in Fig. 17 a-1 was printed with the aim of showing the effect of overheating. It was printed with the same deposition parameters but using short and constant interlayer dwell times of $3 \mathrm{~s}$, without forced air cooling. The final height of the object was $90 \mathrm{~mm}$, which was $10 \%$ shorter than desired. In addition, the layers were noticeably thicker towards the top, with an average thickness of $5.1 \mathrm{~mm}$ compared with the wall thickness of $4.7 \mathrm{~mm}$ of the object printed with temperature control (Fig. 17 b-1). It can be observed that the printed object maintains the desired geometry for the first half of the layers. Very noticeable shape distortions started from the middle of the object upwards, where the object's diameter was smallest. At this point, the object was already overheated, so that the applied layers are lower and wider than desired. Next to this, increased surface waviness can be observed with a large amount of spatter balls on the surface (Fig. 17 a-2). Increasing offset between the programmed and the deposited height led to an increased distance between the object and the deposition nozzle, which had a negative effect on the stability of the deposition process. The third printed object demonstrates the effect of overcooling (Fig. $17 \mathrm{c}-$ 1). The object is printed without temperature control with the same deposition parameters but with long and constant interlayer dwell times of $120 \mathrm{~s}$ and forced air cooling. The average height of this object was $105 \mathrm{~mm}$, which is $5 \%$ more than desired. The deposits were overcooled, so the layer interpass temperature was lower than $100{ }^{\circ} \mathrm{C}$ through all the layers. With the same deposition parameters, the layers were higher and narrower since the deposition volume was constant. The average wall 


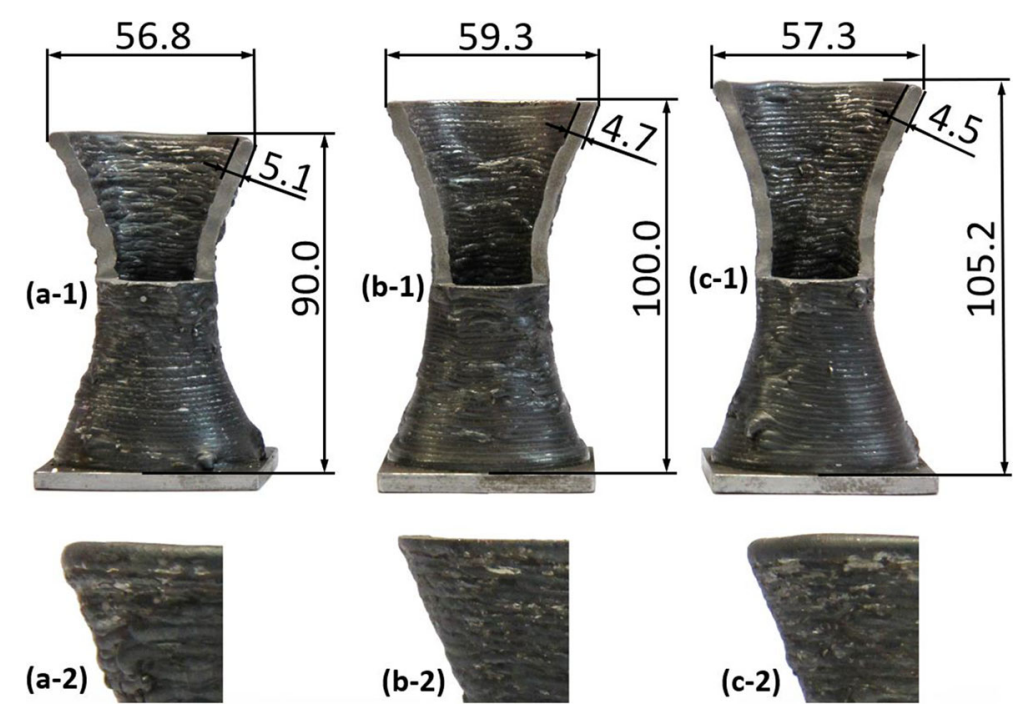

Fig. 17 The object printed with (a) constant $3 \mathrm{~s}$ interpass dwell times and no cooling, (b) same as in Fig. 15, printed with temperature control and forced air cooling, (c) constant $120 \mathrm{~s}$ interpass dwell times and forced air cooling

thickness was $4.5 \mathrm{~mm}$ compared with the wall thickness of $4.7 \mathrm{~mm}$ of the object printed with temperature control (Fig. 17 b-1). These two extreme cases show how layer interpass temperature effects the final shape and illustrate the importance of interpass temperature control between the layers, even for a relatively insignificant material such as the one used in this study.

The main objective of this study was to print small, near-net-shape objects. Once the deposition parameters and interpass temperature are chosen to produce the correct layer shape, maintaining the interpass temperature through all layers is critical to achieve a repeatable deposition height through the layers and the desired final dimension of the deposits. Small objects are typically overheated so that cooling of the deposit is sufficient to maintain the interpass temperature. However, if the interpass temperature cannot be maintained due to a large size or complicated shape of the object being printed, deposition becomes unstable, resulting in shape variations and new issues which include variable contact-tip-to-workpiece distance that affects the deposition current and voltage and thus the heat input, which additionally changes the temperature and shape of the deposit as demonstrated by this study. To address such issues, additional adaptive deposition control must be implemented.

An additional advantage of the proposed system is in the fact that temperature control ensures constant height of the layers. This leads to a quick and easy generation of deposition programmes from CAD models using an open-source path generation software for FDM 3D printers.

\section{Conclusion}

This paper proposes a three-axis WAAM system for affordable printing of small metal components, similar to FDM 3D printers. Material deposition, closed loop interpass temperature control, motion control and forced cooling along the deposition path are integrated using an open-source Linux CNC controller. The simplicity of the system allows the use of an open-source path generation software specifically designed for FDM 3D printers. The system effectiveness together with different control strategies has been evaluated, and the main conclusions are listed below:

(1) Interpass temperature control is critical to achieve repeatable and stable deposition height through the layers and the desired final dimensions of the deposit. The height of the deposited layer depends of the interpass temperature at selected deposition parameters. In the demonstrated case, the experimentally determined deposition parameters and the interpass temperature control at $150{ }^{\circ} \mathrm{C}$ resulted in shape deviations of less than $2 \%$ in comparison with the CAD model. Significant shape distortions occurred due to overheating or overcooling without interpass temperature control at same deposition parameters.

(2) Forced air cooling along the deposition path improved productivity by up to $30 \%$ compared with the deposition without cooling. Cooling is particularly important in reducing the deposit temperature far from the base where air convection is the predominant heat exchange mechanism. Cooling by compressed air is safe and has no adverse effect on the microstructure and mechanical properties of structural steel. 
(3) Path generation software for FDM 3D printers can be used based on the fact that the temperature control ensures constant layer height. This leads to a quick and easy generation of deposition programmes from CAD model, similar to the plug-and-play experience of modern FDM 3D printers.

Funding This work was supported by the Ministry of Higher Education, Science and Technology of the Republic of Slovenia, research programme P2-0270. The research was also supported by Daihen Corporation.

\section{Compliance with ethical standards}

Conflict of interest The authors declare that they have no conflict of interest.

Open Access This article is licensed under a Creative Commons Attribution 4.0 International License, which permits use, sharing, adaptation, distribution and reproduction in any medium or format, as long as you give appropriate credit to the original author(s) and the source, provide a link to the Creative Commons licence, and indicate if changes were made. The images or other third party material in this article are included in the article's Creative Commons licence, unless indicated otherwise in a credit line to the material. If material is not included in the article's Creative Commons licence and your intended use is not permitted by statutory regulation or exceeds the permitted use, you will need to obtain permission directly from the copyright holder. To view a copy of this licence, visit http://creativecommons.org/licenses/by/4.0/.

\section{References}

1. Wong KV, Hernandez A (2012) A review of additive manufacturing. ISRN Mech Eng 2012:10-10. https://doi.org/10.5402/2012/ 208760

2. Williams SW, Martina F, Addison AC, Ding J, Pardal G, Colegrove P (2016) Wire + Arc Additive Manufacturing. Mater Sci Technol 32:641-647. https://doi.org/10.1179/1743284715Y.0000000073

3. Rodrigues TA, Duarte V, Miranda RM, Santos TG, Oliveira JP (2019) Current status and perspectives on wire and arc additive manufacturing (WAAM). Materials (Basel) 12:1121. https://oi. org/10.3390/ma12071121

4. Ding D, Pan Z, Cuiuri D, Li H (2015) Wire-feed additive manufacturing of metal components: technologies, developments and future interests. Int J Adv Manuf Technol 81:465-481. https:// doi.org/10.1007/s00170-015-7077-3

5. Wu B, Pan Z, van Duin S, Li H (2019) Thermal behavior in wire arc additive manufacturing: characteristics, effects and control. 3-18. https://doi.org/10.1007/978-981-13-3651-5_1

6. Montevecchi F, Venturini G, Grossi N, Scippa A, Campatelli G (2018) Idle time selection for wire-arc additive manufacturing: a finite element-based technique. Addit Manuf 21:479-486. https:// doi.org/10.1016/j.addma.2018.01.007

7. Spencer JD, Dickens PM, Wykes CM (1998) Rapid prototyping of metal parts by three-dimensional welding. Proc Inst Mech Eng B J Eng Manuf 212:175-182. https://doi.org/10.1243/ 0954405981515590

8. Yang D, Wang G, Zhang G (2017) Thermal analysis for single-pass multi-layer GMAW based additive manufacturing using infrared thermography. J Mater Process Technol 244:215-224. https://doi. org/10.1016/j.jmatprotec.2017.01.024
9. Zhao H, Zhang G, Yin Z, Wu L (2013) Effects of Interpass Idle Time on Thermal Stresses in Multipass Multilayer Weld-Based Rapid Prototyping. J Manuf Sci Eng Trans ASME 135:135. https://doi.org/10.1115/1.4023363

10. Derekar K, Lawrence J, Melton G, Addison A, Zhang X, Xu L (2019) Influence of interpass temperature on wire arc additive manufacturing (WAAM) of aluminium alloy components. MATEC Web Conf 269:05001. https://doi.org/10.1051/ matecconf $/ 201926905001$

11. Wu B, Pan Z, Ding D, Cuiuri D, Li H, Fei Z (2018) The effects of forced interpass cooling on the material properties of wire arc additively manufactured Ti6A14V alloy. J Mater Process Technol 258:97-105. https://doi.org/10.1016/j.jmatprotec.2018.03.024

12. Henckell P, Günther K, Ali Y et al (2017) The influence of gas cooling in context of wire arc additive manufacturing - a novel strategy of affecting grain structure and size. pp 147-156

13. da Silva LJ, Souza DM, de Araújo DB, Reis RP, Scotti A (2020) Concept and validation of an active cooling technique to mitigate heat accumulation in WAAM. Int J Adv Manuf Technol 107:25132523. https://doi.org/10.1007/s00170-020-05201-4

14. Reisgen U, Sharma R, Mann S, Oster L (2020) Increasing the manufacturing efficiency of WAAM by advanced cooling strategies. Weld World 64:1409-1416. https://doi.org/10.1007/s40194020-00930-2

15. Montevecchi F, Venturini G, Grossi N, Scippa A, Campatelli G (2018) Heat accumulation prevention in wire-arc-additivemanufacturing using air jet impingement. Manuf Lett 17:14-18. https://doi.org/10.1016/j.mfglet.2018.06.004

16. Prado-Cerqueira JL, Diéguez JL, Camacho AM (2017) Preliminary development of a wire and arc additive manufacturing system (WAAM). Procedia Manuf 13:895-902. https://doi.org/10.1016/j. promfg.2017.09.154

17. Song YA, Park S, Choi D, Jee H (2005) 3D welding and milling: Part I-a direct approach for freeform fabrication of metallic prototypes. Int J Mach Tools Manuf 45:1057-1062. https://doi.org/10. 1016/j.ijmachtools.2004.11.021

18. Song YA, Park S, Chae S-W (2005) 3D welding and milling: part II- optimization of the 3D welding process using an experimental design approach. Int J Mach Tools Manuf 45:1063-1069. https:// doi.org/10.1016/j.ijmachtools.2004.11.022

19. Manogharan G, Wysk RA, Harrysson OLA (2016) Additive manufacturing-integrated hybrid manufacturing and subtractive processes: economic model and analysis. Int J Comput Integr Manuf 29:473-488. https://doi.org/10.1080/0951192X.2015. 1067920

20. Nagamatsu H, Sasahara H, Mitsutake Y, Hamamoto T (2020) Development of a cooperative system for wire and arc additive manufacturing and machining. Addit Manuf 31:100896. https:// doi.org/10.1016/j.addma.2019.100896

21. Anzalone GC, Zhang C, Wijnen B et al (2013) A low-cost opensource metal 3-D printer. IEEE Access 1:803-810. https://doi.org/ 10.1109/ACCESS.2013.2293018

22. Nilsiam Y, Sanders P, Pearce JM (2017) Slicer and process improvements for open-source GMAW-based metal 3-D printing. Addit Manuf 18:110-120. https://doi.org/10.1016/j.addma.2017. 10.007

23. Dwivedi R, Kovacevic R (2004) Automated torch path planning using polygon subdivision for solid freeform fabrication based on welding. J Manuf Syst 23:278-291. https://doi.org/10.1016/S02786125(04)80040-2

24. Li Y, Sun Y, Han Q, Zhang G, Horváth I (2018) Enhanced beads overlapping model for wire and arc additive manufacturing of multi-layer multi-bead metallic parts. J Mater Process Technol 252:838-848. https://doi.org/10.1016/j.jmatprotec.2017.10.017

25. Li F, Chen S, Wu Z, Yan Z (2018) Adaptive process control of wire and arc additive manufacturing for fabricating complex-shaped 
components. Int J Adv Manuf Technol 96:871-879. https://oi.org/ 10.1007/s00170-018-1590-0

26. Ultimaker (2019) Cura 3D Printing Slicing Software. https:// ultimaker.com/software/ultimaker-cura. Accessed 1 Oct 2019

27. Michel F, Lockett H, Ding J, Martina F, Marinelli G, Williams S (2019) A modular path planning solution for Wire + Arc Additive Manufacturing. Robot Comput Integr Manuf 60:1-11. https://doi. org/10.1016/j.rcim.2019.05.009

28. Cignoni P, Rocchini C, Scopigno R (1998) Metro: measuring error on simplified surfaces. Comput Graph Forum 17:167-174. https:// doi.org/10.1111/1467-8659.00236
29. Xiong J, Yin Z, Zhang W (2016) Forming appearance control of arc striking and extinguishing area in multi-layer single-pass GMAWbased additive manufacturing. Int J Adv Manuf Technol 87:579586. https://doi.org/10.1007/s00170-016-8543-2

Publisher's note Springer Nature remains neutral with regard to jurisdictional claims in published maps and institutional affiliations. 